\title{
Fatigue Criterion to System Design, Life and Reliability
}

\author{
(ALSA-TH-87 J17 \\ HC Ai $2 / M B$ aO 1

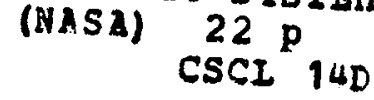

Erwin V. Zaretsky

Lewis Research Center

Cleveland, Ohio

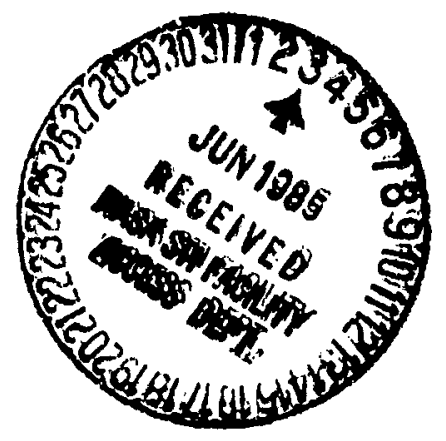

Prepared for the

Twenty-first Joint Propulsion Conference cosponsored by the AIAA, SAE, and ASME Monterey, California, July 8-10, 1985 
Erwin V. Zaretsky

National Aeronatics and Space idministration

Lewis Research Center

Cleveland, Ohio 44735

\section{SUMMARY}

A generalized methodology to structural iffe prediction, design, and reliability based upon a fatigue criterion is advanced. The life prediction methodology is based in part on work of $W$. Weibull and $G$. Lundberg and $A$. Palnigren. The approach incorporates the computed iffe of elemental stress volumes of a complex machine element to predict system ilfe. The results of coupon fatigue testing can be incorporated into the analysis allowing for iffe prediction and comporent or structural renewal rates with reasonabla statistical certainty.

\section{INTRODUCTION}

Design of machine elements is based for the most part on yield stresses and fatigue limiting stresses. In addition to the components material prop.. erties, proper consideration must be given to the effects of notches, surface conaition, component size, residial stress, temperature, duty cycle and environmiental factors such as corrosive or chemical exposure. For most machine eiements, individuals and organizations usually develop design methodology based upon engineering fundamentals found in most machine design texts and factors based upcn their corporate experfence and test data. As a result, it is not too unusual fir different organizations or individuals, starting with the same or similar design requirements to reach dissimilar conclusions or designs while seemingly applying the same fundamental englineering principals to the problem.

Setting aside the subjective creative aspects of design, there appears to be nonuniformity of data from which numbers and design factors are selected as well as differences in the computer codes and boundary conditions used in the to establish fatigue 1 imlts are usually of a limited nature with the conditions under which the data were obtained not adequately defined or reported. Such ftems as temperature, humidity, number of specimens, specimen size and volume, heat treatment, hardness, surface finish and iffe distribution are not given.

The established fatigue 11 imit for much of the reported data is a mean value. From a statistical viewpoint, the median value is equal to or less than the mean. This can be interpreted as meaning that before a fatigue limit is determined there is a probability that 50 percent or more of the specimens had falled. In other words, even at the fatigue limiting stress, ilfe is finite. of course, experienced design engineers have recognized this for years. They have added safety factors to their design procedure usually based on experience. While these nrocedures are generally adequate they can result in over. designed, oversized, overweight and overcost structures. 
A fundamental principle of good design is to recognize that any structure can fall. However, shouid it fall, it should be designed not to cause personal Injury or secondary damage. In other words, if the structure falls, it falls in a safe or benign manner. Once a structure is designed to fall in a benign manner, it then can be designed for finite life whereby the overali size, weight, and cost can be reduced and still meet the reliablifty requirements of the application.

In view of the aforemention, it becomes the objective of the work reported here?n to advance a generalized methodology for structural ilfe prediction, dcsign, and rellability based upon a fatigue criterion. The life prediction methodology is based in part on the work of W. Weibull (refs. 1 and 2) and G. Lundberg and $A$. Palmgren (refs. 3 to 6 ).

\section{SYMBOLS}

C dynamic load capacity

c stress-life exponent

e Woibull slope, $1 / \alpha$

F probability of fallure

f fallure probability density function

h exponent

L $\quad$ life

$L_{A}$ adjusted life at a 90 .percent probajtilty of survival

I.m mission life

Lio 10-percent life, life at which 90 percent of a population will survive

n load..life exponent

P applied load

$P(x)$ probability for occurrence of extent $x$

$R$ cumulative renewal function

$r$ renewal density function

$S$ probablitty of survival

S1 systam probability of survival

1 dummy variable of integration

$t$ time or time function 
stressed volume

$x \quad$ :Ime function or stress function

$X_{\beta} \quad$ characteristic strength

$X_{\mu} \quad$ stress below which no specimens fall

2 depth to critical maximum shearing stress

- shape parameter

B characteristic ilfe

$Y$ mean time to fallure

$n$ stress cycles to fallure

$\mu$ locatioll parameter or time below which no fallure is expected to occur

$\sigma_{u}$ fatigue $11 \mathrm{mit}$

$\tau$ critical stress

\section{STATISTICAL METHOD}

In the late 1930's (circa 1937) W. Welbull in Sweden attempted to graphicaliy linearize various types of statistical data distributions for small sample sizes. By trial and error, Weibull found that by having the $1 \mathrm{nin} 1 / \mathrm{S}$ as the ordinate and in $X$ as the abscissa, where $S$ is the probability of survival or statistical percent of samples surviving and $X$ is a time function, most engineering data distributions will plot on a straight line (ref. 7). Hence, it became possible for small amounts of data to estimate a generalized population distribution for a population of infinite size. Having empiricaliy determined this, Weibuli developed a theoretical basis for what was to become known as the "Weibull distribution" or "Weibull plot" which was published in 1939 (ref. 1). Weibull (ref. 8) defines the distribution function as "an adequate expression for a large class of phenomena which have the property that the probablility of nonoccurrence of an event is equal to the product of the elementary probabilities,"

$$
S=\exp \left\{-[(X-\mu) / \beta]^{1 / \alpha}\right\}
$$

The function involves three parameters,

a the shape parameter

$B$ the scale parameter

$\mu$ the location parameter

Where a the shape parameter is equal to 1.0 .5 and 0.28 , the respective distributions approximated are exponential, Rayleigh, and normal (Gaussian). A typlcal Welbull plot for rollingelement bearing fatigue data is shown in flgure 1. The slope of the line "e" which is called the "Welbull slope" is 
equal to $1 / a$. For most rolling-element bearing data e equals 1.1 . The loration parameter $\mu$ is a finite time under which there would be a zero probabllity of fallure to occur. If fallure can occur in one stress cycle then the location parameter $\mu$ would be assumed to be zero.

For fatigue data, if $n$ stress cycles to fallure is subsittuted for $x$ in equation (1) and $e$ for $1 / \alpha$, and where $F=1-S$, equation (1) can be written

$$
F=1-\exp \left\{-\left(\frac{n}{\beta}\right)^{e}\right\}
$$

The characteristic life $\beta$ is the 63.2 percent fallure life of the population distribution.

Weibull stated that the probability of survival $S$ could be expressed as

$$
\ln \frac{1}{S} \sim \tau^{c} e^{e} V
$$

where $V$ is the volume representation of stress concentration referred to herein as stressed volume, $T$ is the critical shearing stress and $c$ is an exponent denoting a stress-iffe relation where

$$
\eta \sim \tau^{-c}
$$

The values of $c$ and $e$ can be determined experimentaliy.

The effect of stressed volume can be 117 ustrated wherein two specimens of stress volumes $V_{1}$ and $V_{2}$ respectively are subjected to equal stress $\tau$. If $\eta$ is determined at a probability of survival $S_{7}$, then the probability of survival $S_{2}$ for $V_{2}$ for the life is given by the following expression

$$
s_{2}=s_{1}^{v_{2} / v_{1}}
$$

where $v_{2}>v_{1}$.

For the same probability of survival, the specimens with the larger stressed volume will have the lower $11 \mathrm{fe}$. This principle was applied to successfully normalize rolling-element fatigue data by Carter (ref.9) and Zaretsky (ref. 10). This principle was applied by Grisaffe (ref. 11) in a Weibull analysis of shear bond strength of plasma-sprayed alumina coatings on stainless steel ( $\mathrm{fig} .2$ ). Grisaffe showed that the calculated mean bond strength decreased with increasing test area in accordance with equation (5) (fig. 3). Further, the stress at which no specimens falled could be determined by restating equation (1) as follows: 


$$
F_{x}=1-\exp \left[-\left(\frac{x-x_{\mu}}{x_{\beta}}\right)^{e}\right]
$$

where the parameters are now defined as

Fx statistical percent of specimens which when tested at one set of conditions, fall at given stress or lower

$x \quad$ stress

$X_{\mu}$ stress below which no specimens falled

$X_{\beta}$ characteristic strength

e Weibuli slope

\section{LUNDBERG - PALMGREN THEORY}

Lundberg and Paimgren were contemporaries of Weibull. A problem existed in the roliing-element bearing industry to establish the lives of these bearings short of extensive testing. Taking the Weibull approach a step further, Lundberg and Palmgren (ref. 3) took equation (3) and added another element, the depth to the critical maximum shearing stress, $z$ where

$$
\ln \frac{1}{s} \sim \frac{\tau^{c}{ }_{n}^{e} v}{z^{h}}
$$

The rationale for including the depth 2 was that the initiation of a fatigue crack occurred at the depth 2 and that the distance the crack needs to travel to the surface until a spall ( $p$ it) occurs is equivalent to a critical crack length. In other words the greater the distance the maximum shearing stress below the surface the longer it takes for a fatigue crack to propagate to the surface, the longer the fatigue $11 \mathrm{fe}$. Lundberg and Palmgren took the rolling bearing geometry, kinematic, stress theory of Hertz (ref. 12) and Thomas and Hoersch (ref. 13) and incorporated then into equation (7) to obtain a series of equations which relate the roling-element fatigue $11 \mathrm{fe}$ of a bearing to the applied load wherein the resiltant 11 fe would be in millions of inner race revolutions. Krowing the speed of the bearing the $11 \mathrm{fe}$ in hours can be determined. Lundberg and Palmgren further refined their approach to bearing life prediction to include a fictitlous load designated $C$, the dynamic load capdcity. The dynanic load is the theoretical load which when applied to the bearing would result in a life of one million inner-race revoluttons and where

$$
C=P \sqrt[n]{L_{10}}
$$


L10 10-percent 11fe, 11fe at a 90-percent probability of survival, inner-race revolutions

$n \quad l o a d-11$ fe exponent usually taken as 3.

Equation (8) can be written:

$$
L_{10}=\left(\frac{c}{p}\right)^{n}
$$

Hence, the predicted life of a bearing can be determined by knowing $C$ and $P$.

The Lundberg-Palmgren theory is now an international standard used by every manufacturer of bearings around the world (ref . 14). The theory has been applied to other machine elements and mechanical transmission systems (refs. 15 to 28). Table 7 is a list of applications of the Lundberg-Paimgren theory to life prediction.

\section{SYSTEM LIFE AND RELIABILITY}

The life and relibability of a system is based upon the lives and reliabilities of all of its components. Having determined the ilfe of the ind 1 vidual components using Lunberg-Palmgren, the probability of survival of the entire system is as follows

$$
s_{1}=s_{1} \cdot s_{2} \cdot s_{3} \ldots s_{n}
$$

The system life-reliability equation can be written as follows

$$
\ln \frac{1}{S_{T}}=\ln \frac{1}{0.9}\left[\left(\frac{L}{L_{1}}\right)^{e_{1}}+\left(\frac{L}{L_{2}}\right)^{e_{2}}+\left(\frac{L}{L_{3}}\right)^{e_{3}} \ldots+\left(\frac{L}{L_{B}}\right)^{e_{n}}\right]
$$

where $L_{1}, L_{2}, L_{3} \ldots . L_{n}$ are the lives of each component of the system at a 90 percent probabli1ty of survival. The system 11 fe $L$ can be determined at each system probability of survival $S_{T}$. For a 90-percent probabllity of survival

$$
1=\left(\frac{L}{L_{1}}\right)^{e_{1}}+\left(\frac{L_{-}}{L_{2}}\right)^{e_{2}}+\left(\frac{L}{L_{3}}\right)^{e_{3}} \ldots+\left(\frac{L}{L_{n}}\right)^{e_{n}}
$$

\section{MISSION LIFE}

A system does not usually operate at one constant load in actual service. Miner's Rule is used to sum fatigue damage of a mission profile consisting of loads and time-at-loads. For a given probability of survival, the mission life for the system $L_{m}$ is

$$
L_{m}=\left(\frac{t_{a}}{L_{a}}+\frac{t_{b}}{L_{b}}+\frac{t_{c}}{L_{c}}+\frac{t_{d}}{t_{d}}\right)^{-1}
$$


where $t_{a}, t_{b}, t_{c}$ and $t_{d}$ are the fraction of the total time at loads $P_{a}, P_{b}, P_{c}$ and $P_{d}$, respectively, and $L_{a}, L_{b}, L_{c}$ and $L_{d}$ are the system lives at a given probablilty of survival at loads $P_{a}, P_{b}, P_{c}$ and $P_{d}$. respectively. Welbull plot or distribution can be constructed using this method by determining the mission ilfe at varying probabilities of survival. This inethod was used by Lewickl to determine the fatigue 11fe of a turboprop reduction gearbox (ref. 28 ). The analysis was compared io actual field data. The results of this comparison are shown in figures 4 and 5 .

\section{COMPONENT REPLACEMENT RATE}

The Weibull analysis is a valuable tool for predicting the life of components or systems. The arlalysis would describe the fallure rate in field service only if ali components were put into service at the same time and if falled components were not replaced. But, a certain number of components must be kept in operation, fallure rates with replacements is of interest. As an example, if there are 10000 bearings in the field, the user or manufacturer must know how many spare bearings will be needed over a given period in order to keep 10000 bearings in operation at all times. Over the interval of service operation it may take 15000 replacements to keep all 10300 bearings running. The Welbull analys is can never exceed 100 percent, but fleld fallures can and often do exceed 100 percent (ref. 19).

The cumulative probablitity of fallure for the first time, assuming constant service conditions, is a function of the length of time that the bearing has been running. Faliure is the complimentary function to survival according to the following relation:

$$
F(t)=1-S(t)
$$

The probability density function for fallure is

$$
f(t) \equiv \frac{d f}{d t}
$$

The instantaneous probability of failure for the first time in any time interval from $t$ to $t+\Delta t$ is then given by

$$
P(f \text { irst fallure in } \Delta t \text { interval) }=f(t) \Delta t
$$

By using renewal theory (refs. 29 and 30 ), the probability of having to replace a bearing in the fleld is written as follows:

$$
P(\text { making a replacement })=r(t) \Delta t
$$

where $r(t)$ is called the renewal density. The renewal density is calculated from the following summation (ref. 29):

$$
r(t)=\sum_{k=1}^{X} f_{k}(t)
$$

where $f_{k}(t)$ is the $k$-fold convolution of $f$ with itself and is computed by the following recurrence relation (ref. 29): 


$$
f_{k+1}(t)=\int_{0}^{t} f_{k}(T) f_{1}(t-T) d T \quad\left(f_{1} \equiv f\right)
$$

The expression $f_{k}(t) \Delta t$ gives the probability of a $k$ th fallure occurring in the time interval $t$ to $t+\Delta t$. Since, when a fallure occurs, it can be for any value of $k$, it follows that the renewal density function should be defined as the sum over all the $f_{k}$ 's.

The total number of replacements made during the first $t$ units of time is obtain by integrating the renewal density function as follows:

$$
R(t)=\int_{0}^{t} r(T) d T
$$

For a group of bearings that has been operating for some time with fallures occurring and replacements being made, it is also important to know the MTBF (mean time expected between fallures). Arcording to the renewal density theorem (ref. 30),

$$
\lim _{t \rightarrow \infty} r(t)=\frac{1}{\int_{0}^{\infty} t f(t) d t} \equiv \frac{1}{\gamma}
$$

Therefore, the mean time between fallures is calculated as

$$
\text { MTBF }=\frac{y}{\text { totdl number of bearings }}
$$

Reference 19 reports the use of a computer program to evaluate equation (18) for rolling-element bearings. A Weibull slope of 1.1 was assumed. Figure 6 shows plotted results, which give the renewal density function for a case of where the falled bearings are removed from service and replaced with new or restored bearings. For comparisun, the probability densi.y for fallures with no replacement (Weibull density function) is plotted also. The area under the curves represents the probability of fallure.

The functions plotted in figure 6 were numerically integrated and are shown plotted in figure 7. These are the cumulative functions for renewal or fallure. The cumulative renewal functions indicate 100 percent replacement bearings will have been needed by the time 8 L 10 intervals have elapsed. By comparison, at the time of 8 L 10 the Weibuli distribution shows only 65 percent of the original bearings will have falled. The difference in total fallures would be due to replacement bearings falling.

The mean time between fallure (MTBF) frofin equation 2? can be obtained from figure 6. The MTBF is the inverse of the probablitity density for fallure. As an example a probability density for fallure of 0.12 would give a MTBF value of $8.3 \mathrm{~L} / 0$.

\section{FAGIGUE LIFE MODELING}

The Welbull and Lundberg-Palmgren analyses have been primarlly applied to high cycle fatigue with the materlal subjected to a Hertzlan stress field. However, as indicated in reference 11, the Welbull analysis call be applied to 
other types of durablilty problems. What is linportant is that a material e leinent. unly knows the state of stress it is subjected to and not whether it is in a bearing, gear, shaft, compressor or turbine. The crack propagation time in high cycle fatigue is generally a smal? fraction of the total time to fallure. In low cycle fatigue, the crack propagation time is gerierally a signiflcant fraction of the time to fallure. In either case, the end result is total fracture of the component making it no longer useful for its intended purpose. If the fallure distribution is within standard statistical ranges, then it can be represented by the Weibull analysis. Hence, the analysis should be blind to high or low cycle ratigue. This was recognized by loannides and Harris (ref. 3i). Using Weibull and Lundberg-Palmgren, they intruduced a "fatigue limiting stress" and integrated the computed ilfe of elemental stress volumes to predict $11 \mathrm{fe}$. This approach ieads to a meithod of applyirig Lundbergpaimigren 11 fe prediction techniques to other components besides those subject to Hertzian loading. It also allows an investigator to use the results of coupon testing to predict the 1 ife of complex shaped components subjected to nonHertzian cyclic stressing. Ioannides and Harris (ref. 31) applied their analysis successfully to rotating beam fatigue (fig. 8), tlat beams in reversed bending ( $\mathrm{fig} .9$ ) and beams in reverse torsion. Based upon their approach or a modification thereof, design procedures for structures subjected to fatigue loading can be formulated which allows for finite life determination in the initial design stage with reasonable statistical certainity.

\section{DESIGN OF COMPLEX STRUCTURES}

In recent years, finite element stress analysis of complex structures subjected to thermal and mechanical loading has reach a high degree of sophistication and reliablitty. Now computers perform calculations in mere seconds and minutes for problems which only a short time ago would take hours or be impossible to perform. An example of a turbine blade analyzed using finite element analysis is shown in figure 10. Each element of material has associated with it a stress. For design purposes, this stress is within certain established stress or strain limits. The ultimate life of the component is usually based upon empirical calculations or extrapolation from field experience. The results are at best highly speculative. By subjecting the component to expensive product improvement programs (PIP) and by "make and break" techniques, component lives over a products $11 \mathrm{fe}$ time can usualiy be extended to the useful life of the product.

The key to cost effective design is to be able to maximumize component iffe and minimize cost at the completion of the final design stage without the need for extensive testing or field experience. It is proposed that this objective can be accomplished as follows:

(1) Having determined the stress of each elemental volume of a component using finite-element anaiysis, it is possible to establish a iffe of the elemental stressed volume using either equation (3) or (7).

(2) Using equation (12) it is then possible to establish the life of the entire component.

(3) Carrying the process a step further, applying the principle of equation (8) a "dynamic" capacity of the component can be determined. 
(4) Once the dyriamic capacity is determined, the mission ilfe of a com. ponent or system can be established using equation (13).

(5) Using renewal theory (eqs. (18) and (22)), the number of replacements required over a systems useful $11 \mathrm{fe}$ and the mean time between fallures (MTBF) can be determined.

By design iteration, design 1 ife can be maximized and cost minimized. Further, by knowing faliure rates, production guidelines can be set prior to a product entiring the market place.

In the area of bearing technology, vast technological improvements occurred between initial publication of Lundberg-Palmgren (1947) and contemporary development. These technological improvements were factored into the analysis by the use of 11 fe adjustment factors (ref. 32) wherein the adjusted life $L_{A}$ at a 90 -percent probability of fallure is

$$
L_{A}=(D)(E)(F)(G)(H)\left(\frac{C}{P}\right)^{n}
$$

where the life adjustment factors are

D Materials Factor

E Processing Factor

F Lubrication Factor

$G$ Speed Effect

H Misalignment Factor

A similar approach in the design of power-transmitting shafts was taken by Loewenthal iref. 33). The Loevienthal approach is based on a fatigue 11 imiting stress based on combined torsion, bending, and axial loading. The fatigue limiting stress is modified by ten factors which in principle are in part incorporated in the Weibull and Lundberg. Palmgren analyses. Those iactors outside the anaiysis can be based upon experimental coupon fatigue data.

Most machine elements are subjected to their maximum design load only for a very small faction of their mission life cycle. Hence, by designing to a iffe criterion and a mean cubic load rather than a fatigue limiting stress, it is possible to reduce the size of the machine element without a reduction in system reliability.

\section{CONCLUSION}

A generalized methodology to structural life prediction, design, and rellablility based upon a fatigue criterion is advanced. The life prediction methodology is based in part on work of $W$. Welbull and $G$. Lundberg and $A$. Palingren. The approach incorporates the computed life of elemental stress volumes of a complex machine element to predict system 11fe. The results of coupon fatigue testing can be incorporated into the analysis allowing for life prediction and component or structural renewal rates with reasonable statistical certainty. 
1. Weibull, w., "The thenomenon of Rupture in Sollds," Ing. Vetanskaps Akad.-Hando 1., No. 153, 1939.

2. Weibu11, W., "A Statistical Distribution of Wide Applicab1lity," Trans. ASME, J. App 1. Mech., vol. 18, 1951, pp. 293-297.

3. Lundberg, G., and Palmgren, A., "Dynamtc Capacity of Rolling Bearings" Ing. Vetanskaps Akad.-.Handi. no. 196, 1947.

4. Lundberg, G., and Palmigren, "Dynamic Capacity of Rolling Bearings, "Aeta Polytechnica, Mechanical Engineering Series, vol. 1, no. 3, 1947.

5. Lundberg, G., and Palmgren, A. "Dynamic Capacity of Rolling Bearings," Trans. ASME, J. Appl. Mech., vol. 16, no. 2, 1949, pp. 165-172.

6. Lundberg, G. ana Palmgren, A., "Dynamic Capacity of Roller Bearings," Acta Polytechnica Mechanical Engineering Series, vol. 2, no. 3, 1952.

7. Welbu11, W., Personal Communication, Jan. 23, 1964.

8. Weibul1, W., "Efficlent Methods for Estimating Fatigue Life Distributions of Roller Bearings," Bidwel\}, J.B., ed.. Rolling Contact Phenomena, Elsevter, N.Y., N.Y., 196\%, pp. 252-265.

9. Carter, T.L.. "Preliminary Studies of Rolling-Contact Fatigue Life of High-Temperature Bearing Materials," NASA RME57Ki2, Apri1. 1958.

10. Zaretsky, E.V., Anderson, W.J., and Parker, R.J., "The Effect of Contact Angle on Rolling-Contact Fatigue and Bearing Load Capacity, "ASLE Trans., vol. 5, May 1962, pp. 210-219.

11. Grisaffe, S.L., "Analysis of Shear Bond Strength of Plasma-Sprayed Alumina Coatings on Stainless Steel," NASA TND-3113, 1965.

12. Hertz, H., Miscellaneous Papers. Part V-The Contact of Elastic Solids. The MacMilian Co., (London), 1896, pp. 146-162.

13. Thomas, H.R. and Hoersch, V.A., "Stresses Due to the Pressure of One Elastic Solid Upon Another," Univ. I11., Eng. Experiment Station Bull., vol. 27 , no. 46, July 15,1930 .

14. International Standards Organization, "Rolling Bearings-Dynamics Load Rating and Rating Life-Part 1: Calculation Methods," International Standard $281 / 1-1977(E)$.

15. Coy., J.J., Townsend, D.P., and Zaretsky, E.V., "Analysis of Dynamic Capac1ty of Low-Contact-Ratio Spur Gears Using Lundberg-Paimgren Theory," NASA TN D-8029, 1975.

16. Coy, J.J, and Zaretsky, E.V., "Life Analysis of Helic.al Gear Sets using Lunberg-Paimgren Theory, NASA TN D-8045, 1975. 
17. Coy, J.J., Townsend, D.P., ana Zaretsky, E.V., "Dynamlc Lapacity and Surface Fatigue LIfe for Spul and Helical Gears, "ASME Trans. J. of Lubrication Tecinology, vo1. 38, no. 2, pp. 267-276, 1976.

18. Coy. J.J., Loewentha 1, S.H., and Zaretsky, E.V., "Fatigue Life Analysis for Traction Drlves with Application to a Toroldal Type Geometry," NASA TN D-8362, December 1976.

19. Coy, J.J., Zaretsky, E.V., and Cowg1?1, G.R., "Fatigue Life Analysis of Restored and Refurbished Bearings," NASA TN D-8486, May 1977.

20. Townsend, D.P., Coy, J.J., and Zaretsky, E.V., "Experimental and Analytical Luad-Life Realtion for AISI 9310 Steel Spur Gears," ASME Trans. 3. Mechanical Design, vol. 100, no. 1, pp. 54-60, January 1978.

21. Rohn, D.A., Loewenthal, S.H., and Coy. J.J., "Simplified Fatigue Life Analysis foi Traction Orive Contacts," ASME Trans. Mechanical Design, vol. 103, no. 2, pp. 430-439, Apr 11 1981.

22. Coy, J.J., Rohn, D.A., and Loewenthal, S.H., "LIfe Analysis of a Nasvytis Multiroller Planetary Traction Drive," NASA TP-1710, Apri1 1981.

23. Coy, J.J., Iownsend, D.P., and Zaretsky, E.V., "An Update on the Life Analysis of Spur Gears," Advanced Power Transmission Technology, Fischer, $G . K$, ed., NASA CP-2210, pp. 421-433, 1982.

24. Rohn, D.A., Loewenthal, S.H., and Coy, J.J., "Sizing Criteria for Traction Drives," Power Transmission Technology, Fischer, G.K, ed., NASA CP-2210, Pp. 299-315, 1982.

25. Savage, M., Paridon, C.A., and Coy, J.J., "Rellabllity Model for Planetary Gear Trains," ASME Trans. J. Mech. Trans. and Automation in Design, vol. 105, no. 3, Sept, 1983, pp. 291-397

26. Savage, M., Knorr, R.J., and Coy, J.J., "Life and Rellability Models for Hellcopter Transmissions," AHS Paper AHS-RWP-16, NoV. 1982.

27. Rohn, D.A., Loewentha1, S.H., and Coy. J.J., "Short Cut for Predicint Traction-Drive Fatigue Life," Machine Design, vol. 55, no. 17, pp. 73-77, 1983.

28. Lewick1, D.G., Black, J.D., Savage, M. and Coy, J.J., "Fatigue Life Analysis of a Turboprop Reduction Gearbox, "NASA TM-87014, 1985.

(Presented at AIAA/SAE/ASME Jo1nt Propulsion Conference, Cincinnat1, June $11-13,1984$.

29. Bralow, R.E., Proschan, F., and Hunter, L.C., Mathematical Theory of Rellabllity, John Wlley and Sons, Inc., 1965, pp. 48-6\%.

30. Lloyd, D.K., and Llpow, M., Rellabllity: Management Metherds and Mathematics, Prentice-Ha11, Inc., 1962, pp. 271-278.

31. Ioannides, E., and Harris, T.A., "A New Fatigue Life Model for Rolling Bearlings," ASMF paper 84-Trtb-28, 1984 (to be published in ASME Trans., J. Tr1b., 1985). 
32. Bamberger, E.N., et a1.. Life Adjustinent Factors for Ball and Roller Bearlngs-Air Engineering Design Gilite, ASME, N.Y., 1971.

33. Loewenthi1, S.H., "Design of Power Transmitting Shafts," NASA RP-1123, Juty 1984.

TABLE 1. - LUNDBERG-PALMGREN FATIGUE LIFE ANALYSIS [Based upon 1939 Weibull theory.]

\begin{tabular}{|l|c|}
\hline \multicolumn{1}{|c|}{ Analysis } & Year published \\
\hline Bearings & 1947 \\
Spur gears & 1975 \\
Helical gears & 1976 \\
Restorad and refurbished bearings & 1977 \\
Loda-life relation & 1978 \\
Toroidal drive (traction) & 1976 \\
Optimization of nlultiroller traction drive & 1980 \\
Simplified life analysis for traction drives & 1980 \\
Nasvytis arive & 1981 \\
Spiral bevel gears & 1982 \\
Planetary assemblies & 1982 \\
Transmission assemblies & 1983 \\
Rotary beam, torsion x tension-compression & 1984 \\
\hline
\end{tabular}




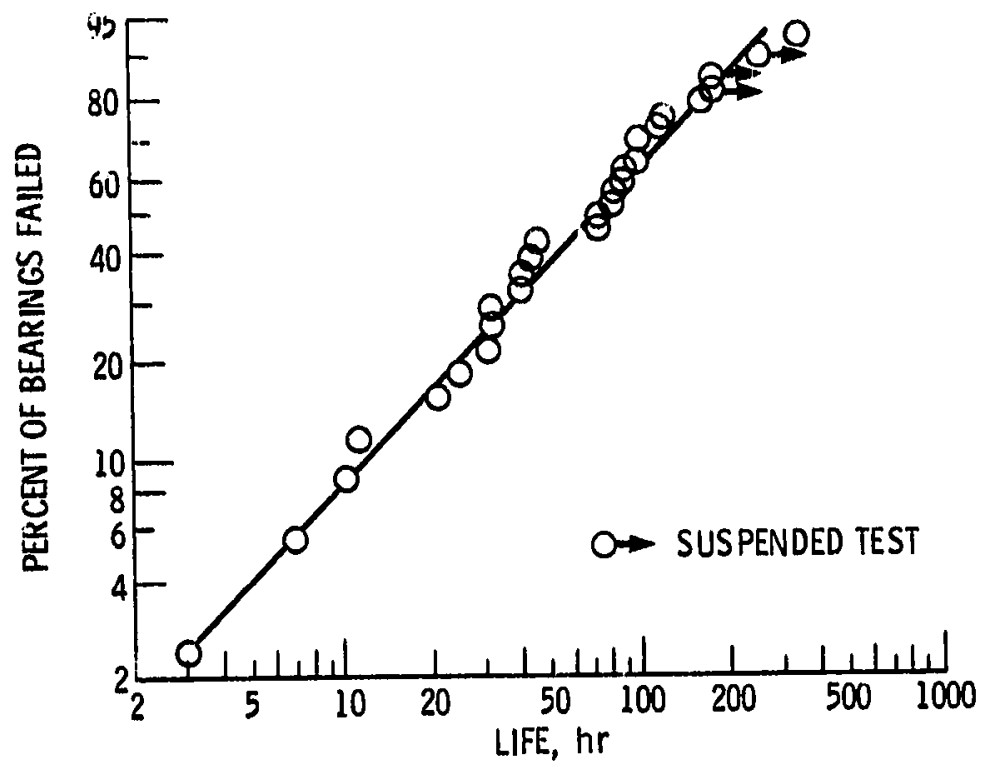

Figure 1. - Weibull distribution of bearing fatigue life for $140-\mathrm{mm}$ bore-size angular-contact ball bearing. MiL-L-7808 lubricant; thrust load, 9500 lbs; speed, $10000 \mathrm{rpm}$; temperature, $122^{\circ} \mathrm{C}\left(250^{\circ} \mathrm{F}\right)$.

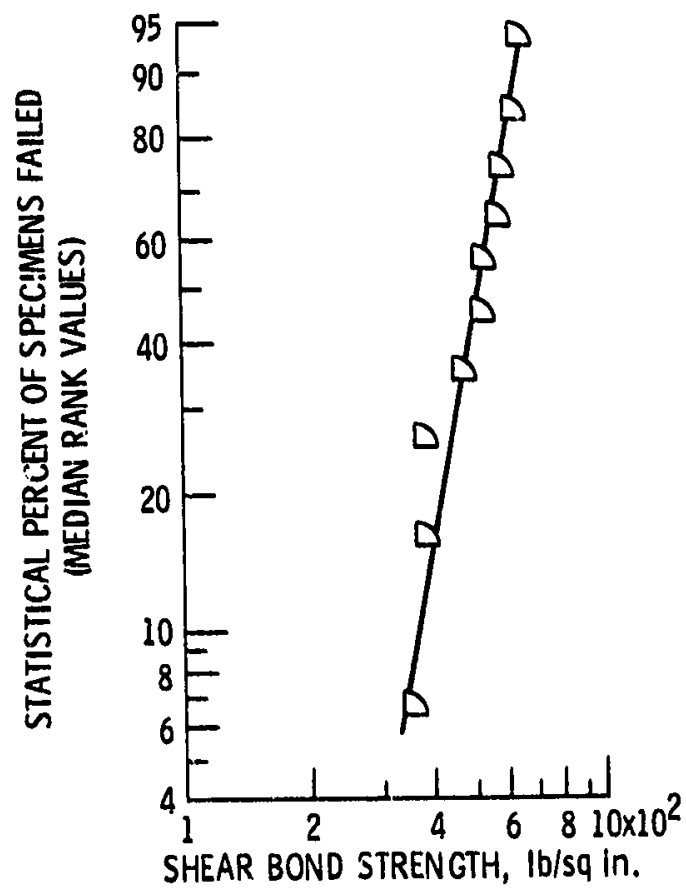

Figure 2. - Weibull distribution for bond-shear-strength for coating of spray powder on stainless steel (ref. 11). 


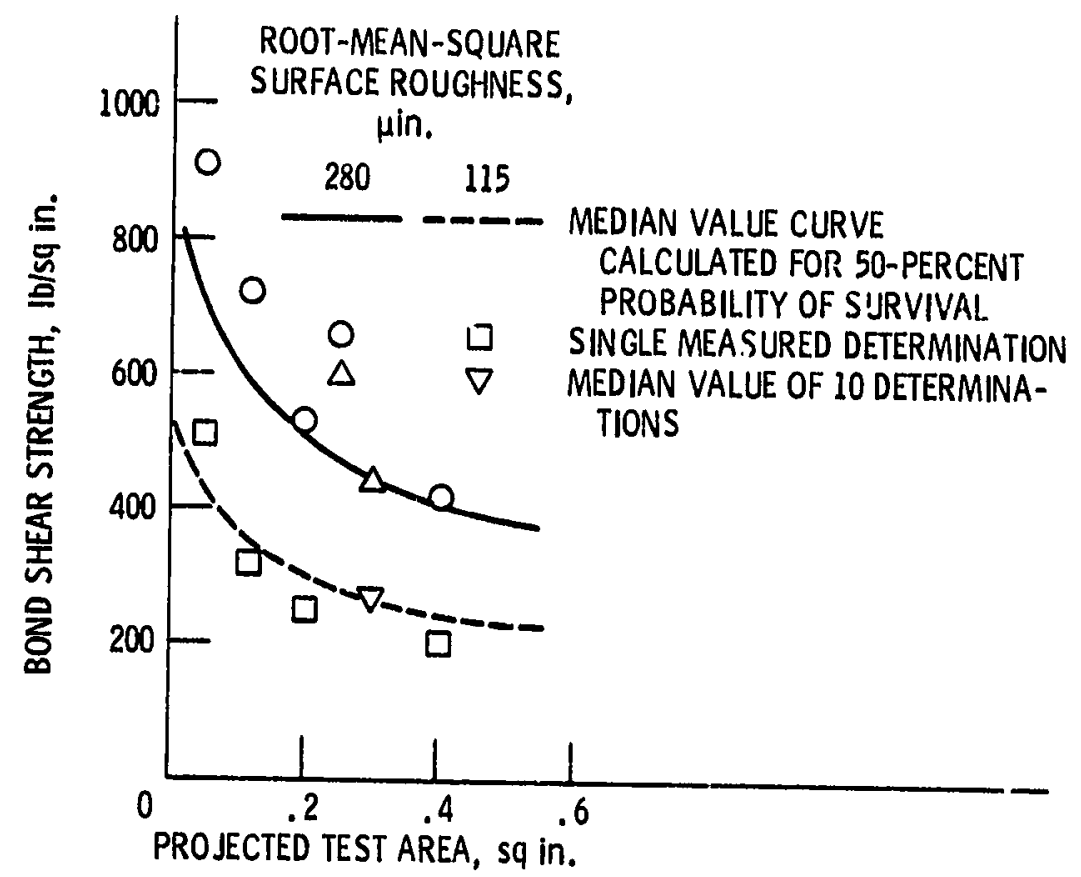

Figure 3. - Effect ol projected test area on measured and calculated bond shear strength of coatings at two surface roughnesses (ref. 11).

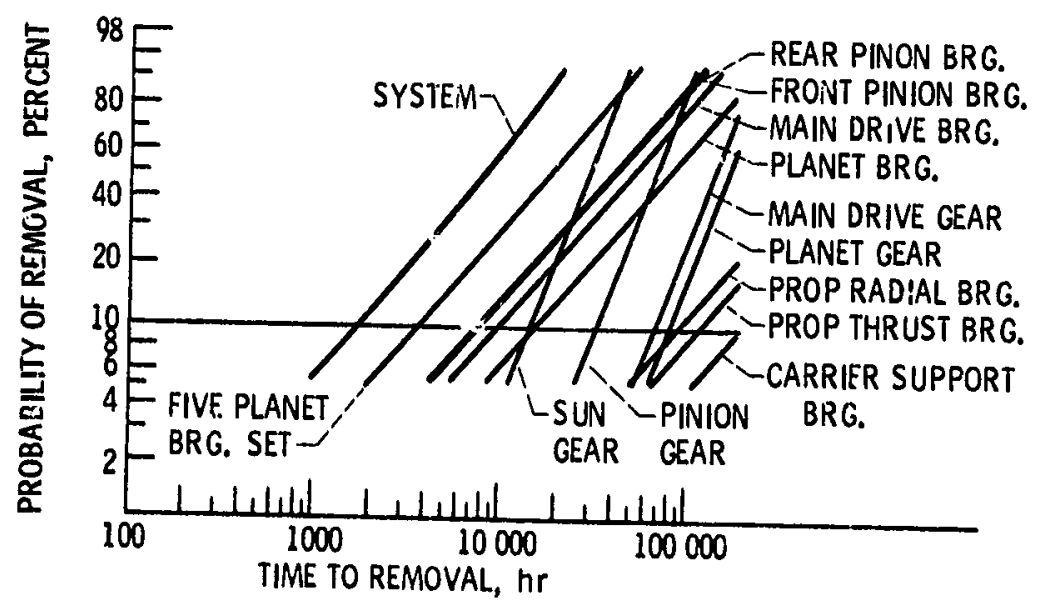

Figure 4. - Analytically predicted system and component fatigue mission lives. Combined material and material processing life adjustment factors used for bearings. Gear material is baseline material-no factors needed. No lubrication liie adjustment factors used (ref. 28). 


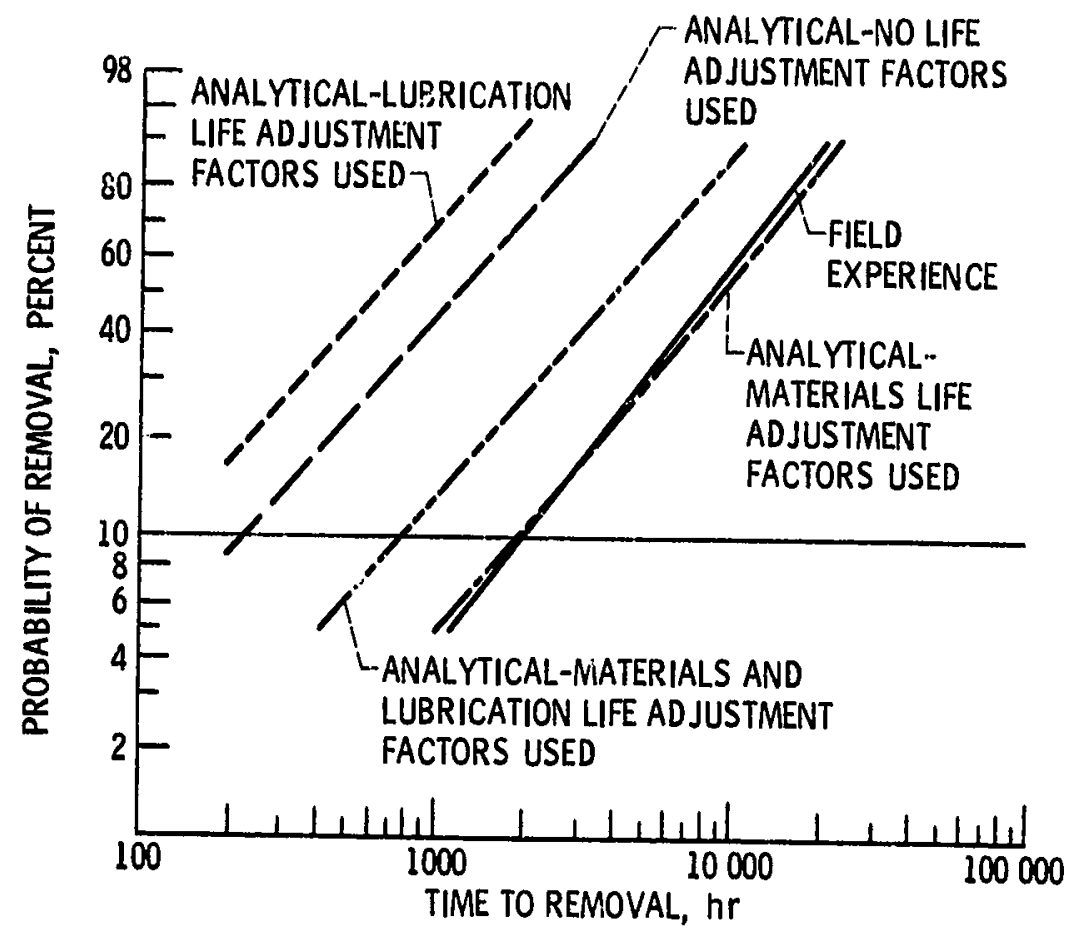

Figure 5. - Turboprop reduction gearbox fatigue lives (field experience) compared with analytically predicted system mission lives. Material factor implies combined material and material processing factor.) (Ref. 28.)

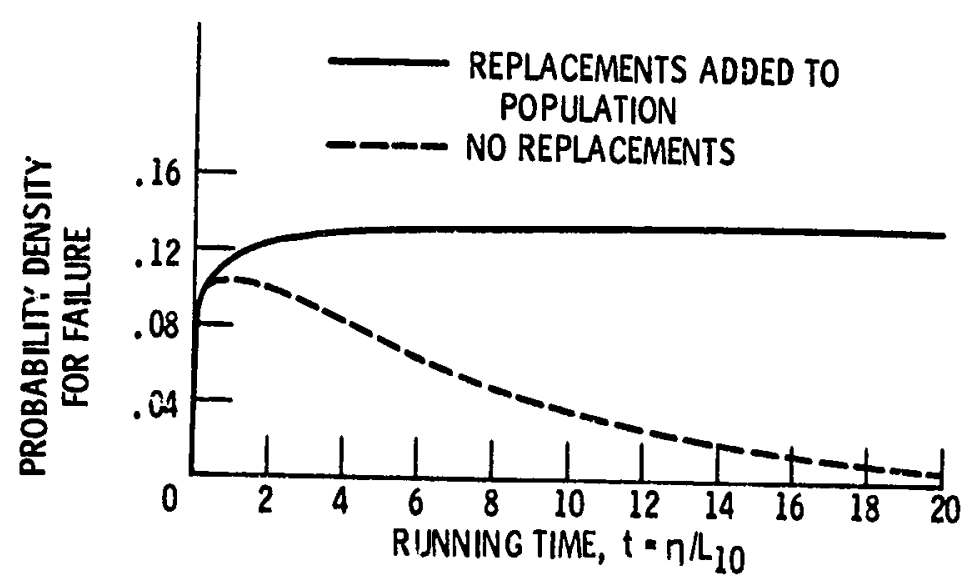

Figure 6. - Renewal density functions compared for rolling-tlemont bearings. Also shown is probabillty density for fail ure of new bearing assuming no replacements. Area under curves represents probability of failure. 


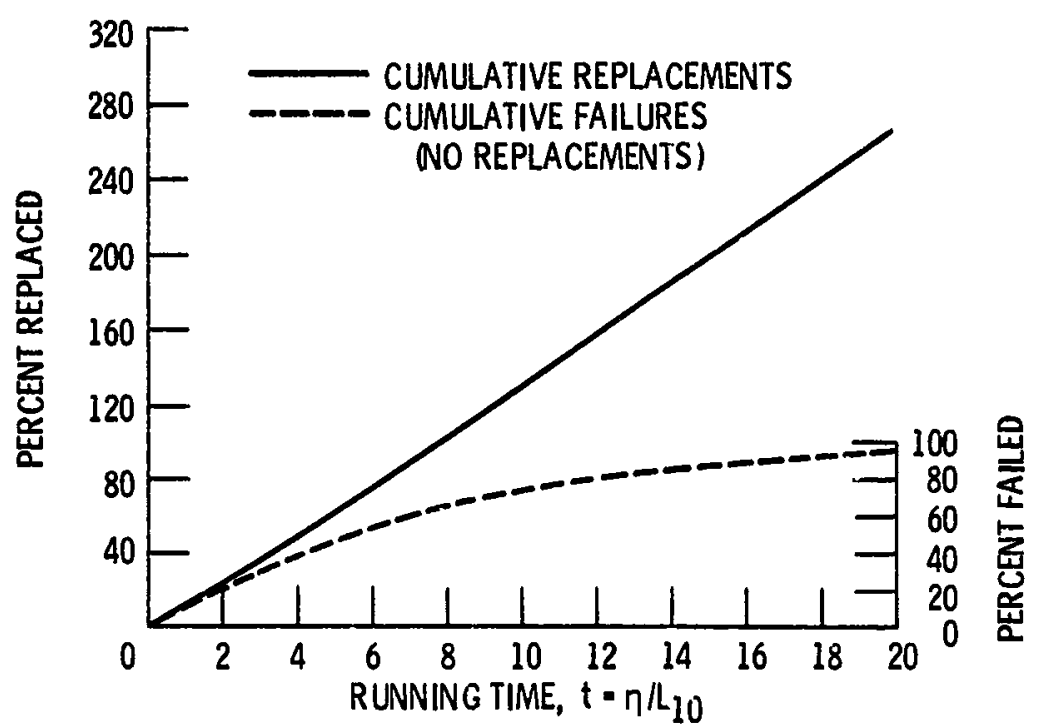

Figure $\bar{\tau}$. - Cumulative renewal and failure for rollingelement bearings. 


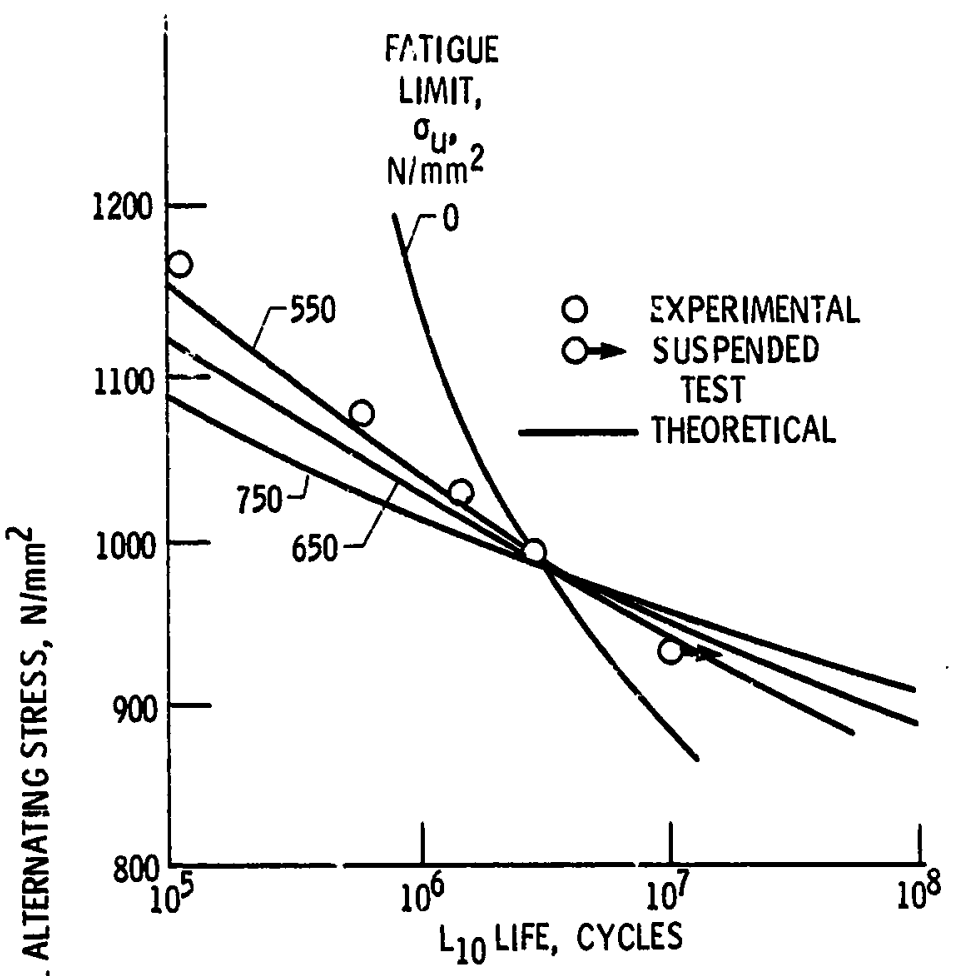

(a) Martensitic steel.

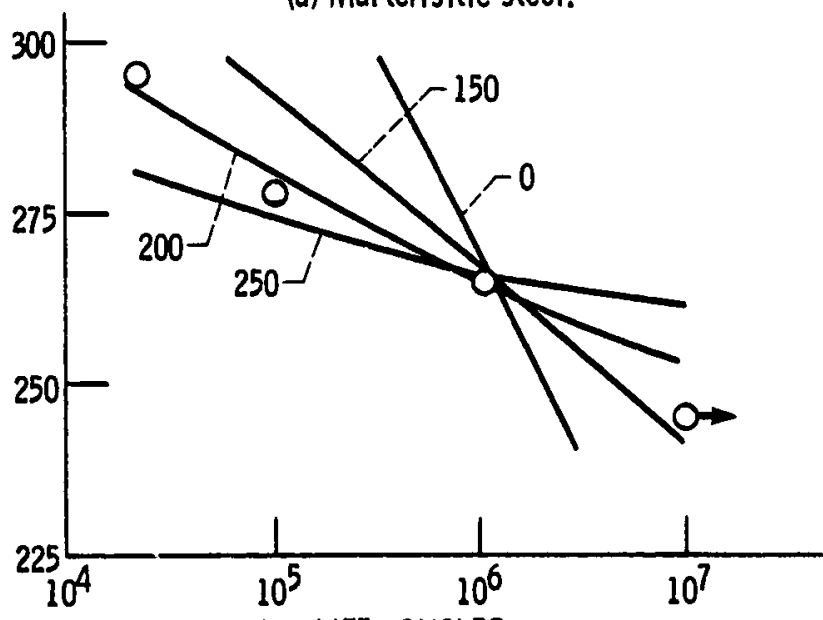

$L_{10}$ LIFE, CYCLES

(b) Soft annealed steel.

Figure 8. - Comparison between experimental and predicted stress-life relation for AISI 52100 steel rotating beam specimens for calculated values of fatigue limit $\sigma_{u^{\prime}}$ (Ref. 31.) 


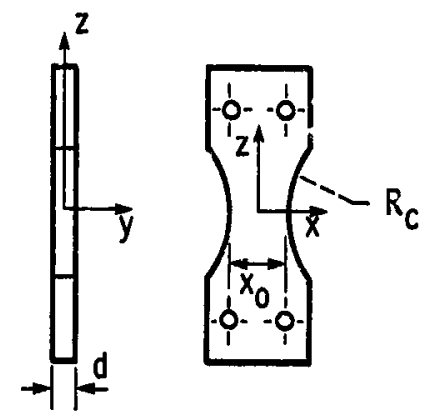

(a) Flat beam configuration.

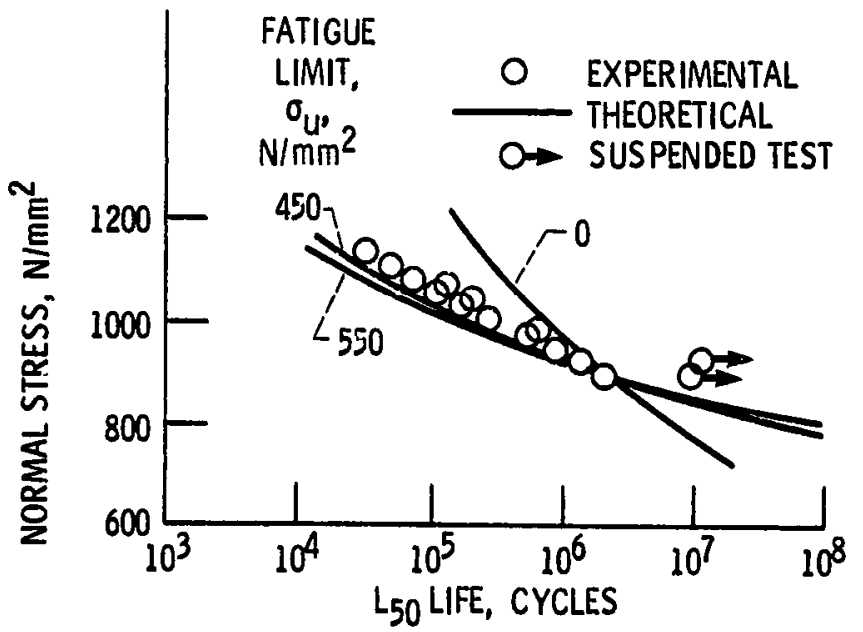

(b) Stress-life relationship for calculated values of fatigue limit $\sigma_{\mathrm{u}}$.

Figure 9. - Cumparison between experimental and predicted stress-life relation for flat beam specimens made from bearing steel and tested in reverse bending (ref. 31). 


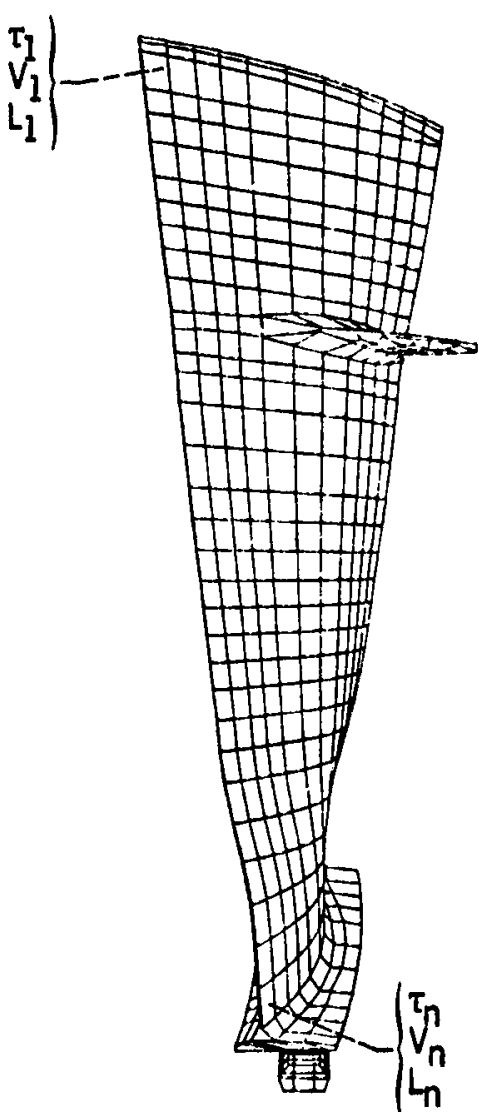

Figure 10. - Finite element analysis of turbine engine fan blade. 


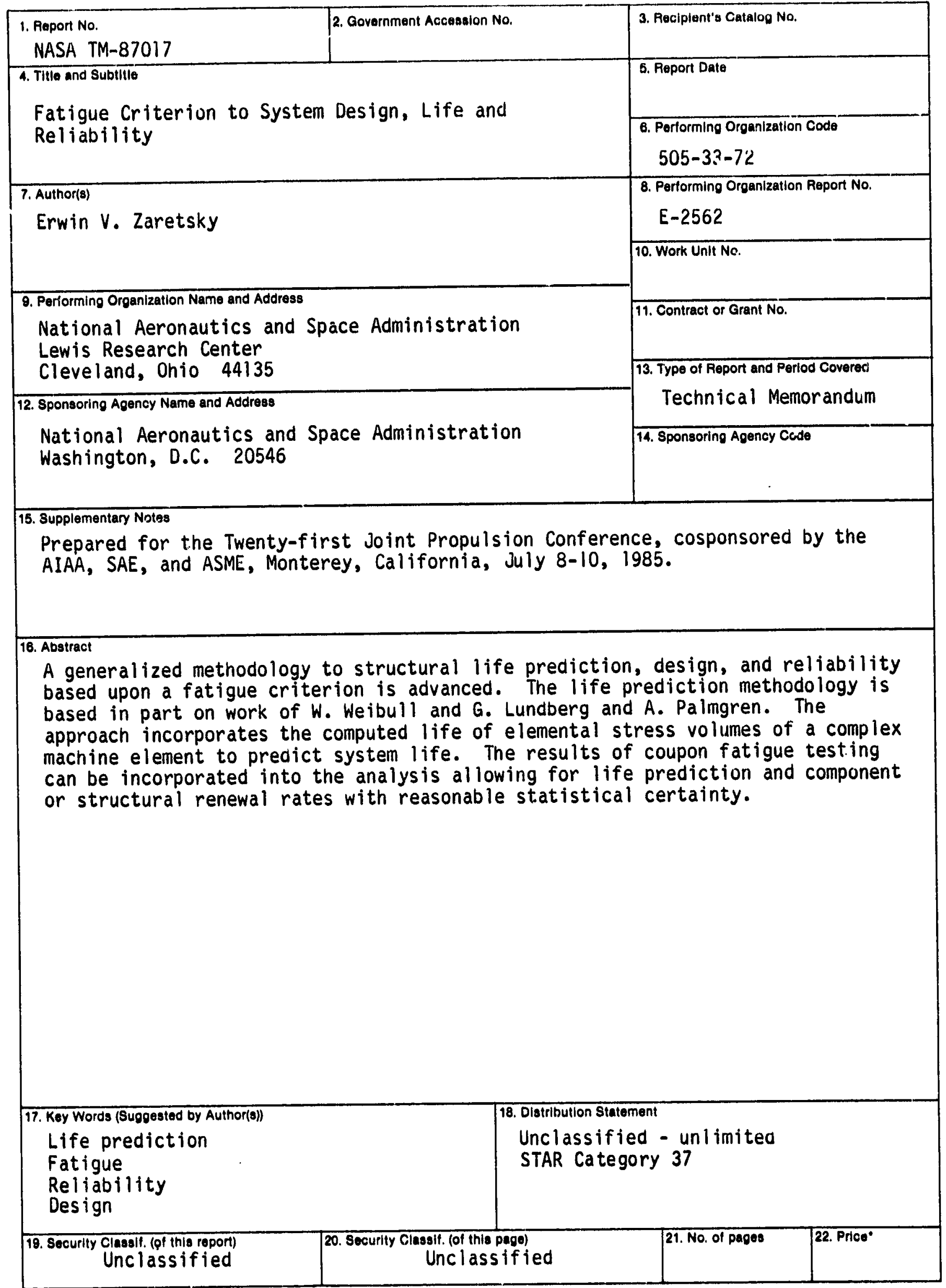

"For sale by the National Technical Information Service, Springfield, Virginia 22161 